\title{
Rheumatoid arthritis-associated interstitial lung disease
}

\section{Joshua J Solomon \\ Kevin K Brown}

Autoimmune Lung Center and Interstitial Lung Disease Program, National Jewish Health, Denver, CO, USA
Correspondence: Joshua J Solomon National Jewish Health, 1400 Jackson St, Denver, CO 80206

$\mathrm{Tel}+\mid 303398$ I62 I

Fax +I 3033981040

Email solomonj@njhealth.org
This article was published in the following Dove Press journal:

Open Access Rheumatology: Research and Reviews

5 March 2012

Number of times this article has been viewed

\begin{abstract}
Rheumatoid arthritis (RA) is a systemic inflammatory disorder affecting $1 \%$ of the US population. Patients can have extra-articular manifestations of their disease and the lungs are commonly involved. RA can affect any compartment of the respiratory system and high resolution computed tomography (HRCT) of the lung is abnormal in over half of these patients. Interstitial lung disease is a dreaded complication of RA. It is more prevalent in smokers, males, and those with high antibody titers. The pathogenesis is unknown but data suggest an environmental insult in the setting of a genetic predisposition. Smoking may play a role in the pathogenesis of disease through citrullination of protein in the lung leading to the development of autoimmunity. Patients usually present in middle age with cough and dyspnea. Pulmonary function testing most commonly shows reduced diffusion capacity for carbon monoxide and HRCT reveals a combination of reticulation and ground glass abnormalities. The most common pattern on HRCT and histopathology is usual interstitial pneumonia (UIP), with nonspecific interstitial pneumonia seen less frequently. There are no large-scale well-controlled treatment trials. In severe or progressive cases, treatment usually consists of corticosteroids with or without a cytotoxic agent for 6 months or longer. RA interstitial lung disease is progressive; over half of patients show radiographic progression within 2 years. Patients with a UIP pattern on biopsy have a survival similar to idiopathic pulmonary fibrosis.
\end{abstract}

Keywords: rheumatoid arthritis, interstitial lung disease, nonspecific interstitial pneumonia, usual interstitial pneumonia, anti-CCP

\section{RA background and review}

Rheumatoid arthritis (RA) is a systemic autoimmune disorder characterized by destructive joint disease as well as extra-articular (ExRA) manifestations. The disease is common; it affects $1 \%$ of the US adult population and the likelihood of RA increases with age. It is three times more common in women and the prevalence varies by geographic location. ${ }^{1}$ RA has a heritability of greater than $50 \%$ and has been associated with more than 30 specific genetic regions. ${ }^{1,2}$ Smoking is the primary recognized environmental risk factor and doubles your likelihood of disease. ${ }^{3} \mathrm{RA}$ is characterized by the presence of specific autoantibodies, rheumatoid factor (RF) and antibodies against citrullinated proteins (anti-CCP). Anti-CCP antibodies have a specificity of $95 \%{ }^{4}$ and they can predate the development of clinical evidence of RA; up to $40 \%$ of patients have anti-CCP antibodies prior to developing symptomatic joint disease. ${ }^{5}$

Survival in patients with RA is lower than that seen in the general population, with older age, male gender, and ExRA (including subcutaneous nodules, Sjögren's syndrome, Keratoconjunctivitis sicca, and pulmonary fibrosis) being risk factors for early 
mortality. ${ }^{6-8}$ ExRA are common, with a prevalence approaching $40 \% .{ }^{9}$ Though cardiovascular disease and infection are responsible for the majority of deaths in RA, ${ }^{10-12} 10 \%-20 \%$ of deaths appear directly related to pulmonary disease ${ }^{13-16}$ and, in patients with RA and clinically significant pulmonary involvement, over $80 \%$ of deaths are due to their lung disease. ${ }^{17}$ Despite improvements in the management of RA, there have been no substantial improvements in overall mortality. ${ }^{18}$

\section{Pulmonary manifestations of RA}

Any of the anatomic compartments of the lung - airways (bronchiectasis, bronchiolitis), vasculature (pulmonary hypertension, vasculitis), pleura (pleuritis, effusions) or parenchyma (rheumatoid nodules, interstitial lung disease [ILD]) (Table 1) can be primarily or directly affected by RA. Patients are also at risk for secondary pulmonary complications, with drug toxicities during treatment and opportunistic infections from immunosuppressive therapy being the major concerns. ${ }^{19}$

Respiratory symptoms such as breathlessness and cough are common in RA, reported in nearly half of patients, and, when present, correlate with pulmonary physiologic abnormalities. ${ }^{20}$ In asymptomatic or randomly selected patients, $27 \%-63 \%$ will have pulmonary function testing

Table I Pulmonary manifestations of RA

\begin{tabular}{l} 
Airways \\
- Bronchiectasis \\
- Bronchiolitis (constrictive, follicular) \\
- Cricoarytenoid arthritis \\
Vascular \\
- Pulmonary hypertension \\
- Vasculitis \\
Pleura \\
- Pleurisy/pleural effusions \\
- Pneumothorax \\
- Empyema \\
Parenchymal \\
- Rheumatoid nodules \\
- Interstitial lung disease \\
- Organizing pneumonia \\
Drug-induced lung disease \\
- MTX \\
- Gold \\
- D-penicillamine \\
- Sulfasalazine \\
Miscellaneous \\
- Infections from immunosupression \\
- Amyloidosis \\
- Fibrobullous disease \\
- Caplan's syndrome (associated with pneumoconiosis) \\
- Secondary Sjögren's syndrome \\
\hline
\end{tabular}

(PFT) abnormalities. ${ }^{21-24}$ Patterns include airflow limitation, restriction, or isolated reductions in diffusion capacity for carbon monoxide (DLCO). ${ }^{21,22,24,25}$ Despite the large number of patients with measurable physiologic impairment, most abnormalities remain clinically insignificant and asymptomatic patients with PFT abnormalities generally don't show physiologic progression over 10 years. ${ }^{23}$ High resolution computed tomography (HRCT) abnormalities are even more common, with $50 \%-81 \%$ of unselected patients showing pathologic changes, ${ }^{21,22,25-30}$ particularly airways disease, ${ }^{25,28-30}$ and interstitial disease. ${ }^{21,22,26,27}$ The likelihood of HRCT abnormalities depends upon the presence of respiratory symptoms; asymptomatic patients will have abnormalities in $48 \%-68 \%$ of HRCTs $\mathrm{s}^{21,26,27}$ and symptomatic patients have abnormalities in up to $90 \% .{ }^{21,26}$ HRCT abnormalities are even seen in healthy nonsmokers with early RA ( $<1$ year), with evidence of airways disease most commonly seen. ${ }^{31}$ HRCT is also more sensitive than pulmonary physiology in detecting pulmonary abnormalities as PFTs are normal in 37\% of patients with abnormal HRCT scans. ${ }^{22}$ Bronchoalveolar lavage (BAL) is abnormal in $40 \%-50 \%$ of patients ${ }^{32,33}$ with an increase in helper $\mathrm{T}$ lymphocytes and lower levels of macrophages, B lymphocytes, and suppressor T-cells (leading to an increased $\mathrm{CD} 4 / \mathrm{CD} 8$ ratio). ${ }^{34}$

Patients with RA may develop lung disease from the medications used to treat the joint disease, with reports of pulmonary toxicity from gold, ${ }^{35}$ penicillamine, ${ }^{36}$ bucillamine, ${ }^{37}$ leflunomide, ${ }^{38}$ methotrexate, ${ }^{39,40}$ sulfasalazine, ${ }^{41}$ infliximab, ${ }^{42,43}$ and tacrolimus. ${ }^{44,45}$ Methotrexate (MTX) use is associated with an incidence of interstitial pneumonitis of $1 \%-3 \% .{ }^{46,47}$ There is an associated slight decline in forced expiratory volume in 1 second $\left(\mathrm{FEV}_{1}\right)$ and forced vital capacity (FVC) in RA patients taking MTX $^{46}$ but studies looking at PFTs and HRCTs in RA have had mixed results, with some showing declines in function and others showing no clinically significant effect. ${ }^{22,24,48-51}$ There have also been reports of an increased frequency of MTX pneumonitis after initiation of infliximab therapy. ${ }^{52,53}$ While rituximab has been linked to rare but severe infections in RA, most of these in the lung, ${ }^{54}$ the risk of developing infections seems to be comparable to that of other anti-TNF and biologics. ${ }^{55}$

\section{RA-ILD History}

The first description of ILD in a patient with RA dates back to 1948 when Ellman and Ball described three RA patients with "reticulation" on chest radiographs, two of whom had interstitial fibrosis on postmortem exam. ${ }^{56}$ The first case of 
"rheumatoid lung" was reported in 1961, describing the clinical, radiographic, and spirometric characteristics of a single patient. ${ }^{57}$ Subsequent case reports and case studies sought to draw a connection between clinical RA and ILD but were limited at the time by the sensitivity of the detection methods (plain chest radiographs) and debate on the relationship between RA and ILD. ${ }^{58,59}$ When single breath diffusion studies were combined with chest radiographs, the reported incidence of disease increased (up to $40 \%$ in one study). ${ }^{60}$ In 1972, Popper and colleagues further solidified the relationship when they prospectively evaluated RA patients with chest radiographs and physiology and found abnormalities in $33 \% .{ }^{61}$ Since then, numerous studies have found a strong association between RA and ILD. ${ }^{33,62-67}$

\section{Risk factors for RA-ILD}

The lifetime risk for developing ILD in the setting of RA is approximately $8 \%$ compared to $1 \%$ in the general population. ${ }^{68}$ Multiple risk factors for its development have been identified (Table 2). Smoking is one of the strongest risk factors $^{51,69-71}$ and, in a cohort of 336 patients with RA-ILD, smoking was the most consistent independent predictor of radiographic and physiologic abnormalities suggestive of ILD. $^{70}$ Male gender has been associated with ILD $^{33,70,72-74}$ but this relationship isn't seen in all studies. ${ }^{22,65,75}$ Other documented risk factors include high-titer $\mathrm{RF}^{22,65,76}$ high-titer anti-CCP, ${ }^{77}$ advanced age, ${ }^{22,65}$ genetic background, ${ }^{78,79}$ and the presence of clinically severe RA. ${ }^{22,70,80}$

\section{Prevalence}

The literature reports a wide variance in the prevalence of ILD in RA. The prevalence depends on clinical phenotype (eg, the presence or absence of respiratory symptoms), gender (more men would likely favor more ILD), duration of disease, clinical severity of RA, percentage of smokers, autoantibody profile, history of treatment, and the methods of diagnosis. Early studies utilizing chest radiographs found a prevalence of ILD of $1 \%-5 \% .^{57,69,81}$ Subsequent studies

Table 2 Risk factors for ILD in RA

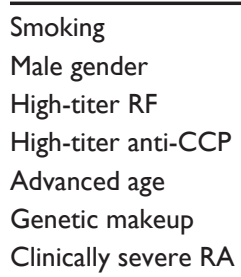

Abbreviations: anti-CCP, anti-cyclic citrullinated peptide; ILD, interstitial lung disease; RA, Rheumatoid arthritis; RF, rheumatoid factor. screened patients irrespective of symptoms and have found a prevalence ranging from $19 \%-58 \%{ }^{33,65,70}$ In patients with a documented lack of symptoms of lung disease, the prevalence is lower at $44 \% .{ }^{33}$ Lung biopsies performed on hospitalized patients with RA found interstitial changes in $80 \%$, with half of these patients having no symptoms. ${ }^{63}$

\section{Pathogenesis}

The pathogenesis of RA-ILD is unknown. The available data points to the presence of an environmental insult in the setting of a genetic predisposition. Though the data is limited, HLA-B54, HLA-DQB1*0601, HLA-B40, and HLA-DR4 as well as the site that encodes for the $\alpha 1$-protease inhibitor have all been linked to lung disease in RA. ${ }^{78,79,82-84}$ With this genetic predisposition, there is evidence of immune dysregulation with alterations in both $\mathrm{T}$ and $\mathrm{B}$ cells. Patients with RA-ILD have higher levels of CD4+ cells and CD54+ $T$ cells in their lungs when compared to patients with one of the idiopathic interstitial pneumonias (IIPs), suggesting a maladaptive immune response and chronic $\mathrm{T}$ cell activation. ${ }^{85,86} \mathrm{~B}$-cells are also involved, as patients with RA have higher levels of CD20 positive B-cells in peribronchiolar lymphoid aggregates. ${ }^{87}$ Histopathologically, more germinal centers and lymphoplasmocytic cellular inflammation and fewer fibroblast foci are seen when compared to the IIPs. ${ }^{88}$ The cytokine milieu is also different in these patients. Patients with RA and established fibrosis have lower levels of IFN- $\gamma$ and TGF- $\beta 2$ than those with no ILD or mild ILD. ${ }^{51}$ In addition, patients with RA-ILD have higher levels of TNF- $\alpha$ and IL- 6 production by macrophages when compared to healthy controls ${ }^{89}$ and PDGF levels are higher in BAL fluid. ${ }^{51}$ Finally, patients with RA-ILD have increased levels of high proliferative potential colony-forming cells in their peripheral blood compared to those without ILD and it is felt that these are possible progenitor cells for alveolar macrophages. ${ }^{90}$

\section{The role of smoking}

Recent attention has been focused on the lungs as a possible site for initiation of the immune dysregulation that leads to clinical RA. Smoking is an established risk factor for the development of $\mathrm{RA}^{91}$ as well as the development of RA-ILD. ${ }^{51,69-71}$ There has been recent interest in the relationship between citrullinated protein, HLA-DR shared epitopes, smoking, and the development of RA. HLA-DR shared epitopes are the major genetic risk factors for the development of $\mathrm{RA}^{92}$ and it was found that smokers with HLA-DR shared epitopes have up to a 21 -fold increase in 
the risk of developing anti-CCP antibody positive RA. ${ }^{93}$ Smokers have citrullinated proteins in their lung lavage fluid $^{94}$ and citrullinated proteins are seen in the synovium of patients with $\mathrm{RA}^{95}$ as well as rheumatoid nodules and the parenchyma of patients with RA-associated ILD. ${ }^{96}$ Smoking increases your likelihood of having anti-CCP antibodies at the onset of RA in a dose-dependent fashion ${ }^{97}$ and there is an increased prevalence of lung disease (predominately ILD) in patients with high-titer anti-CCP antibodies. ${ }^{72}$ This data suggests that, in certain patients with the appropriate genetic predisposition, the immune dysregulation that is seen in patients with RA could originate in the lungs and be related to tobacco smoke-induced citrullination of proteins, leading to the production of autoimmunity and the subsequent development of clinical arthritis. This does not explain all cases, as the development of RA-ILD is not dependent on a history of tobacco use. ${ }^{98}$

\section{Clinical features}

Patients usually present in their late 50 s to $60 \mathrm{~s}^{99-101}$ after an average of 10-12 years with RA. ${ }^{99,101}$ Among all comers with ILD, there is an even split between men and women ${ }^{100,101}$ though there seem to be gender differences among the various histopathologic subtypes of ILD (with men more commonly having usual interstitial pneumonia $[\mathrm{UIP}]^{17,101}$ and women more commonly having nonspecific interstitial pneumonia $\left.[\mathrm{NSIP}]^{102}\right)$. In two-thirds of patients, a confirmed diagnosis of RA precedes the diagnosis of ILD, though ILD can be occasionally precede the joint disease (up to 7 years in one study). ${ }^{101}$ Most patients with ILD will have symptoms such as cough or dyspnea ${ }^{103}$ though preclinical disease is commonly found when looked for by chest imaging or physiology. ${ }^{51}$ Crackles are commonly found on exam and are more frequent than in those RA patients without ILD. ${ }^{51,65,104}$ Finger clubbing is seen less commonly than in patients with idiopathic pulmonary fibrosis (IPF). ${ }^{66}$

\section{Pulmonary function testing}

Pulmonary physiologic screening in early RA $(<2$ years duration) irrespective of symptoms finds PFT abnormalities consistent with ILD in $22 \%$ of patients. ${ }^{33} \mathrm{~A}$ reduction in DLCO is the most common finding, ${ }^{33,65}$ may be the earliest physiologic change (those with RA and clinically silent ILD can have isolated reductions in $\mathrm{DLCO}^{33,51}$ ), and correlates with the extent of reticulation on HRCT. ${ }^{75,99}$ A reduction is seen in more than $50 \%$ of all patients screened and in $82 \%$ of those with documented ILD. ${ }^{65,105}$ It has also been found to be a highly specific predictor of disease progression in patients with UIP and RA. ${ }^{106}$ PFTs likely change later than HRCT in the course of disease as patients with preclinical disease can have an abnormal HRCT in the setting of normal PFTs. ${ }^{65}$

\section{Chest imaging}

In patients with RA-ILD, chest X-rays frequently show reticular, reticulonodular or honeycomb changes in the lung bases. ${ }^{107}$ The chest X-ray, however, is insensitive as greater than $50 \%$ of patients who have a normal plain chest radiograph will have abnormalities on their HRCT. ${ }^{33,65}$ Therefore, HRCT has replaced plain chest X-rays in the initial evaluation of the RA patient with potential lung disease. The incidence of ILD on HRCT depends on the clinical phenotype of the population evaluated. A study screening nonsmokers without respiratory symptoms found evidence of ILD on HRCT in $33 \% .{ }^{51}$ Early RA ( $<2$ years duration) patients have evidence of ILD on HRCT in a third of cases, though the extent of disease is mild. ${ }^{33}$ In both early and longstanding RA, HRCT changes can precede changes in PFTs. ${ }^{31,108}$ In looking at patients with clinically suspected ILD (symptoms, impaired lung function, or abnormal CXR), 92\% have HRCT findings consistent with ILD. ${ }^{99}$

The most common abnormal findings are ground glass opacities (GGOs) and reticulation, seen in over $90 \%$ of patients, ${ }^{75}$ with reticulation seen in $65 \%-79 \%$ of HRCTs ${ }^{99,109}$ and seen in isolation in long-standing disease. ${ }^{99}$ GGOs are seen in $27 \%$ of patients, rarely seen in isolation (reported as the only HRCT abnormality in 0/49 HRCTs in one study), and are more common in patients with a shorter duration of disease. ${ }^{99}$ Less common findings include honeycombing, traction bronchiectasis, nodules, centrilobular branching lines, and consolidation. ${ }^{75,109}$ Patterns of involvement on HRCT correspond to patterns identified in the IIPs (Figures 1 and 2). In patients with RA referred to an interstitial lung disease center, patterns of ILD on HRCT include UIP (40\%), NSIP (30\%), bronchiolitis (17\%), and organizing pneumonia (8\%). ${ }^{75}$ Other studies have found similar percentages of UIP and NSIP. ${ }^{110}$ Occasionally, patients will have more than HRCT pattern. ${ }^{75}$

HRCT findings are well-correlated with underlying histopathology. ${ }^{75,109}$ Reticulation and honeycomb change are associated more frequently with pathologic UIP. ${ }^{75}$ GGOs can be found in both UIP and NSIP but are more pronounced and diffuse in the latter. ${ }^{75}$ Centrilobular branching is seen with bronchiolitis obliterans and consolidation correlates with organizing pneumonia. ${ }^{109}$ There are also associations between HRCT findings and physiology. The degree of 


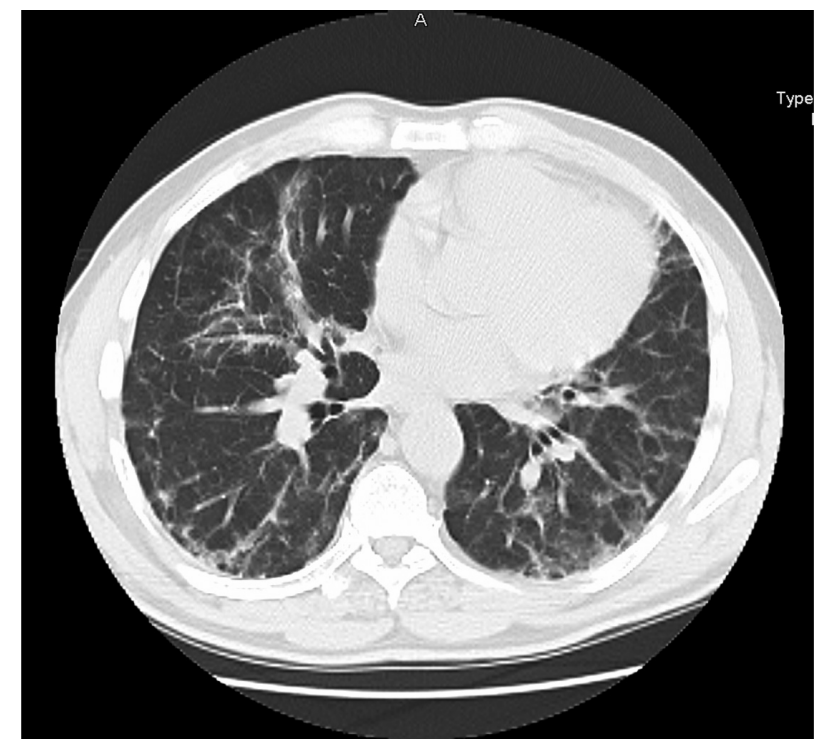

Figure I High resolution computed tomography (HRCT) of RA-ILD with an NSIP pattern. An HRCT of a patient with RA showing peripheral reticulation and ground glass abnormalities with no notable honeycombing.

Abbreviations: RA, rheumatoid arthritis; ILD, interstitial lung disease; NSIP, nonspecific interstitial pneumonia.

parenchymal involvement in RA-ILD is correlated with decreases in $\mathrm{FEV}_{1}, \mathrm{FVC}$, and DLCO ${ }^{99}$ Finally, a recent study found that survival is linked to HRCT pattern as patients with a "definite UIP" pattern had a survival that was significantly worse than those with an indeterminate pattern or a pattern suggestive of NSIP. ${ }^{100}$

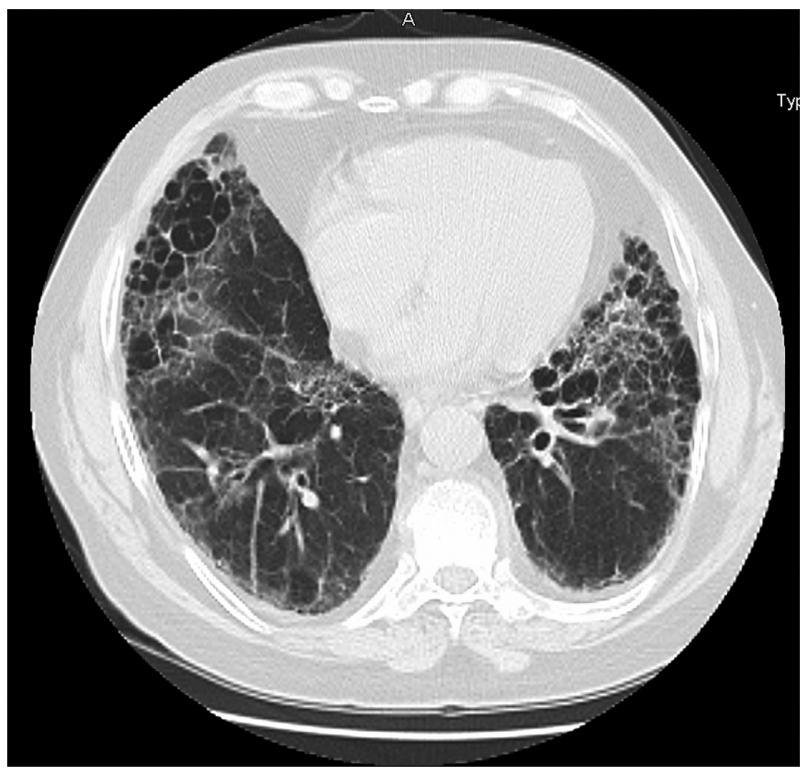

Figure 2 High resolution computed tomography (HRCT) of RA-ILD with a UIP pattern. An HRCT of a patient with RA showing reticulation and significant honeycombing in a basilar and peripheral distribution with an absence of significant ground glass abnormality.

Abbreviations: RA, rheumatoid arthritis; ILD, interstitial lung disease; UIP, usual interstitial pneumonia.

\section{BAL}

Patients with clinically significant RA-ILD have an increase in the total cellular concentration, ${ }^{111}$ increases in neutrophils, lymphocytes, and eosinophils, ${ }^{32,33}$ and a decreased $\mathrm{CD} 4 / \mathrm{CD} 8$ ratio $^{32,111}$ on bronchoalveolar lavage compared to those without ILD. Abnormal BAL findings can also be seen in patients with RA and subclinical ILD ${ }^{112}$ and elevated lymphocyte counts in these patients may help to distinguish them from those with normal physiology and chest radiographs. ${ }^{113}$ BAL findings have only a moderate correlation to the lesions found on HRCT, with a higher number of neutrophils found in patients with GGOs. ${ }^{99}$

\section{Histopathology}

Studies of comparative histopathology in RA-ILD patients are complicated by a significant selection bias, as more severely impaired patients and those with unclear HRCT patterns tend to get surgical lung biopsies. Though NSIP is the most common histopathologic pattern seen in patients with other collagen-vascular associated ILDs, in patients with RA-ILD, UIP is more common than NSIP (60\% vs $35 \%)^{101,114}$ (Figures 3 and 4). Patients with UIP are more likely to be male and current or former smokers when compared to NSIP, ${ }^{17,101}$ though the relationship between smoking and RA-ILD associated UIP is not seen in all studies. ${ }^{100}$ In RAILD associated UIP, fewer fibroblast foci, more inflammation, and a higher number of germinal centers are seen when compared to idiopathic UIP. ${ }^{88}$ Patients with RA-ILD will also have increased CD4+ T-cell infiltrates when compared to the IIPs. ${ }^{85}$ They often have concomitant lymphocytic bronchiolitis ${ }^{115}$ and well-developed bronchus-associated lymphoid tissue. ${ }^{116}$ Occasionally, biopsy specimens in these patients

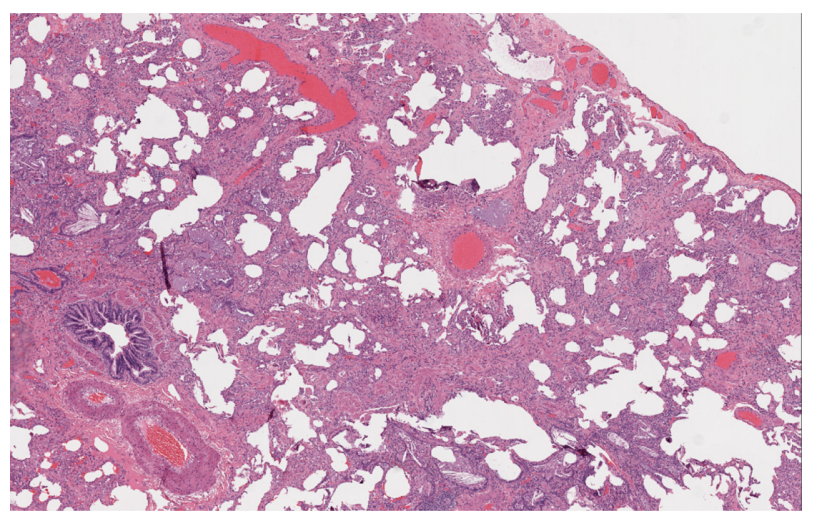

Figure 3 Histopathology in a patient with RA-ILD associated NSIP. A surgical biopsy specimen in a patient with RA showing cellular interstitial infiltrates and fibrosis in a temporally uniform distribution.

Abbreviations: RA, rheumatoid arthritis; ILD, interstitial lung disease; NSIP, nonspecific interstitial pneumonia. 


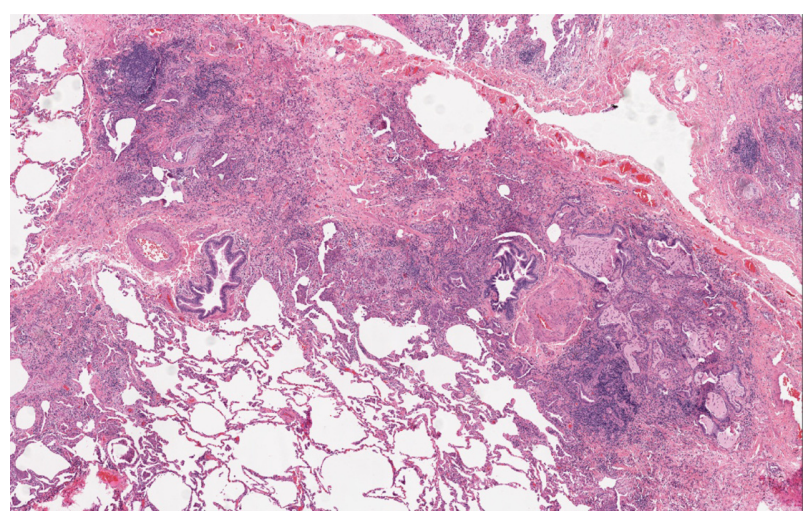

Figure 4 Histopathology in a patient with RA-ILD associated UIP. A surgical biopsy specimen in a patient with RA showing patchy interstitial fibrosis that starts in the peripheral acinar regions and is in close proximity to unaffected lung tissue. Abbreviations: RA, rheumatoid arthritis; ILD, interstitial lung disease; UIP, usual interstitial pneumonia.

will have more than one histopathologic pattern. ${ }^{117}$ Other patterns in RA-ILD have been reported with lesser frequencies, including organizing pneumonia, diffuse alveolar damage, lymphocytic interstitial pneumonia, and desquamative interstitial pneumonia.

\section{Biomarkers}

Biologic fluid-based biomarkers have been looked at in BAL fluid. Patients with early asymptomatic RA-ILD have higher levels of the platelet-derived growth factor-AB and $\mathrm{BB}$ in BAL fluid and those with established UIP on biopsy have lower levels of IFN- $\gamma$ and TGF- $\beta 2 .{ }^{51}$ Patients with progressive disease have higher levels of IFN- $\gamma$ and TGF- $\beta 1 .{ }^{51}$ Levels of KL-6 are higher in patients with RA-ILD associated UIP ${ }^{118}$ as well as other subtypes of RA-ILD. ${ }^{17}$

\section{Treatment}

Rigorous treatment trials in patients with RA-ILD are lacking, and to date there has been no large-scale well-controlled treatment trial. There are limited reports of treatment with methotrexate, ${ }^{119}$ azathioprine, ${ }^{120}$ cyclosporine, ${ }^{121}$ mycophenolate mofetil, ${ }^{122}$ and TNF- $\alpha$ inhibitors. ${ }^{123,124}$ Current treatment regimens are variable and usually include corticosteroids with or without a cytotoxic agent such as azathioprine or mycophenolate mofetil. Treatment duration varies but is usually 6 months or longer.

There have been concerns about the anti-tumor necrosis factor agents and their possible association with the progression of ILD in patients with RA. There have been case reports of exacerbations of existing ILD or new interstitial pneumonitis in patients with RA taking infliximab. ${ }^{43,125,126}$ Etanercept has been linked to granulomatous lung disease and exacerbation of pre-existing lung disease in patients with RA. ${ }^{127,128}$ In spite of these reports, a recent review of 367 patients with RA-ILD treated with either anti-TNF agents or traditional RA treatments found no difference in mortality. ${ }^{129}$

\section{Outcome}

RA-ILD is progressive in the majority of patients; up to $57 \%$ of patients with early asymptomatic RA-ILD had progression on HRCT during a mean follow-up of 1.5 years and $60 \%$ of patients with established RA-ILD and a UIP histopathologic pattern had progression on HRCT during this time frame. ${ }^{51}$ Another study found that $34 \%$ of patients with RA and fibrosing alveolitis progressed radiographically over 24 months of follow-up. ${ }^{106}$ Reduced DLCO has been associated with progression of disease in those patients with a UIP histopathologic pattern, with a DLCO $<54 \%$ predicted demonstrating a $80 \%$ sensitivity and $93 \%$ specificity in predicting progressive disease. ${ }^{106}$ The use of MTX has also been suggested as a risk factor for progression. ${ }^{51}$ In some RA patients, pulmonary fibrosis is rapidly progressive $(25 \%$ in one series $)^{130}$ and patients with pulmonary fibrosis that leads to hospitalization have a median survival of 3.5 years. ${ }^{131}$

Yousem and colleagues were one of the first to report that among RA patients with ILD, those with a histologic pattern of UIP in surgical lung biopsy specimens had the worst prognosis. ${ }^{117}$ Results from subsequent studies have confirmed their findings. ${ }^{101,131} \mathrm{~A}$ recent study found 5-year survival rates of $36 \%$ in patients with UIP and $94 \%$ in NSIP ${ }^{17}$ (with other studies confirming the favorable outcome in NSIP and reporting no fatal cases of RA-ILD associated NSIP $^{17,101}$ ). The prognosis of RA-ILD compared to IPF has long been debated with some studies finding similar outcomes ${ }^{132,133}$ and others suggesting that RA-ILD patients have a longer survival than IPF. ${ }^{104,134}$ Recent studies that have looked at RA patients with UIP on either HRCT or pathology have found a survival similar to that in IPF. ${ }^{100,114}$ In patients with RA-ILD with a UIP histopathologic pattern, the presence of traction bronchiectasis and honeycomb fibrosis, male gender, and a reduced DLCO are associated with a worse survival rate. ${ }^{100}$

\section{Workup and evaluation}

Rheumatologists should have a high index of suspicion for lung disease in all patients with RA. Symptoms such as cough and/or breathlessness and physical exam findings such as crackles significantly increase the likelihood of ILD, and other patient characteristics (such as active smoking, male 
gender, and CCP positivity) should lower the threshold for evaluation. Though patients with limited mobility from their joint disease are at risk of presenting with more severe pulmonary involvement, screening for pulmonary involvement in the asymptomatic patient should occur with a clear plan in mind for dealing with the findings. There is no data to guide the treatment of preclinical disease and is therefore of uncertain benefit. In patients with suggestive signs or symptoms, pulmonary physiology can be useful; however, patients with early and mild disease may have normal PFTs and more sensitive testing for ILD requires an HRCT. Defining the underlying subtype of ILD by histopathologic pattern (NSIP, UIP) is helpful to stratify patients' risk for disease progression and early mortality; however, HRCT patterns are highly predictive of the underlying histopathology and lung biopsy is reserved for cases with atypical clinical or chest imaging features.

Patients with ILD should be referred to a pulmonologist. Smoking patients should be encouraged to quit and MTX should generally be avoided in these patients. Adequate control of a patient's joint symptoms should not be seen as a surrogate for control of the lung disease and does not obviate the need for close lung-specific follow-up for patients with documented lung disease.

It is our practice to treat patients with clinically significant symptoms, or physiologically or radiographically advanced disease on presentation or with evidence of symptomatic, physiologic, or radiographic progression. With a paucity of published data to guide our decisions, treatment at our tertiary referral center is based on clinical experience. Treatment incorporates the clinical importance of controlling joint symptoms and generally consists of a combination of a corticosteroid and a cytotoxic agent such as azathioprine or mycophenolate mofetil. Failure of response to the initial agent is often followed by a trial with the alternative cytotoxic agent. We have treated patients with life-threatening disease with cyclophosphamide, though with mixed results. Anecdotal responses as measured by stability of disease have been noted with rituximab. As with all treatments, sideeffects must be thoroughly discussed with the patients and clinicians should follow the accepted monitoring schedule. A response to therapy generally requires at least 3-6 months of treatment with responses monitored by indices of symptoms, oxygenation, pulmonary physiology, and chest imaging with HRCTs. A response is defined as an improvement in one or more of these indices. Stabilization or a reduced rate of decline may also indicate a response. Other treatment such as comprehensive rehabilitation and maintenance of normoxia as well as a regular search for comorbidities such as silent reflux and obstructive sleep apnea should be considered.

\section{Summary}

Lung disease is common in RA and can involve all compartments of the lung. Up to $80 \%$ of HRCTs of the chest are abnormal, showing predominately airways disease and ILD. ILD is more common in men, advanced age, and those with high-titer CCP. Smoking appears to be involved as it citrullinates proteins in the lung, increases the likelihood of having anti-CCP antibodies, and increases the risk of both RA and its associated ILD. Patients present in their 50s and 60s with symptoms of cough and breathlessness. Infrequently, ILD can precede the development of joint disease. Pulmonary physiologic findings are variable and can show restriction, obstruction, or a reduction in the DLCO. HRCT reveals patterns similar to those seen in the IIPs. Pathology correlates well with findings on HRCT and most commonly reveals UIP (with one-third of patients having an NSIP pattern). UIP in RA differs from the idiopathic form with more germinal centers and fewer fibroblastic foci. There are no large-scale treatment trials for RA-ILD and the existing data comes from case reports and series with varying clinical phenotypes. Patient with UIP have the worst prognosis (5-year survival rate of $36 \%$ ) and a survival that may be similar to those with IPF. Rheumatologists should have a high index of suspicion for lung disease in patients with RA and refer those with abnormal testing to a pulmonologist.

\section{Disclosure}

The authors report no conflicts of interest in this work.

\section{References}

1. Scott DL, Wolfe F, Huizinga TW. Rheumatoid arthritis. Lancet. 2010;376(9746):1094-1108.

2. van der Woude D, Houwing-Duistermaat JJ, Toes RE, et al. Quantitative heritability of anti-citrullinated protein antibody-positive and anticitrullinated protein antibody-negative rheumatoid arthritis. Arthritis Rheum. 2009;60(4):916-923.

3. Carlens C, Hergens MP, Grunewald J, et al. Smoking, use of moist snuff, and risk of chronic inflammatory diseases. Am J Respir Crit Care Med. 2010;181(11):1217-1222.

4. Avouac J, Gossec L, Dougados M. Diagnostic and predictive value of anti-cyclic citrullinated protein antibodies in rheumatoid arthritis: a systematic literature review. Ann Rheum Dis. 2006;65(7): 845-851.

5. Nielen MM, van Schaardenburg D, Reesink HW, et al. Specific autoantibodies precede the symptoms of rheumatoid arthritis: a study of serial measurements in blood donors. Arthritis Rheum. 2004;50(2): 380-386.

6. Radovits BJ, Fransen J, Al Shamma S, Eijsbouts AM, van Riel PL, Laan RF. Excess mortality emerges after 10 years in an inception cohort of early rheumatoid arthritis. Arthritis Care Res (Hoboken) 2010;62(3):362-370. 
7. Gabriel SE, Crowson CS, Kremers HM, et al. Survival in rheumatoid arthritis: a population-based analysis of trends over 40 years. Arthritis Rheum. 2003;48(1):54-58.

8. Turesson C, O'Fallon WM, Crowson CS, Gabriel SE, Matteson EL. Occurrence of extraarticular disease manifestations is associated with excess mortality in a community based cohort of patients with rheumatoid arthritis. J Rheumatol. 2002;29(1):62-67.

9. Turesson C, O'Fallon WM, Crowson CS, Gabriel SE, Matteson EL. Extra-articular disease manifestations in rheumatoid arthritis: incidence trends and risk factors over 46 years. Ann Rheum Dis. 2003;62(8):722-727.

10. Maradit-Kremers H, Nicola PJ, Crowson CS, Ballman KV, Gabriel SE. Cardiovascular death in rheumatoid arthritis: a population-based study. Arthritis Rheum. 2005;52(3):722-732.

11. Koota K, Isomaki H, Mutru O. Death rate and causes of death in RA patients during a period of five years. Scand $J$ Rheumatol. 1977;6(4):241-244.

12. Toyoshima H, Kusaba T, Yamaguchi M. Cause of death in autopsied RA patients. Ryumachi. 1993;33(3):209-214.

13. Minaur NJ, Jacoby RK, Cosh JA, Taylor G, Rasker JJ. Outcome after 40 years with rheumatoid arthritis: a prospective study of function, disease activity, and mortality. J Rheumatol Suppl. 2004;69:3-8.

14. Sihvonen S, Korpela M, Laippala P, Mustonen J, Pasternack A. Death rates and causes of death in patients with rheumatoid arthritis: a population-based study. Scand J Rheumatol. 2004;33(4):221-227.

15. Suzuki A, Ohosone Y, Obana M, et al. Cause of death in 81 autopsied patients with rheumatoid arthritis. J Rheumatol. 1994;21(1):33-36.

16. Young A, Koduri G, Batley M, et al. Mortality in rheumatoid arthritis. Increased in the early course of disease, in ischaemic heart disease and in pulmonary fibrosis. Rheumatology. 2007;46(2):350-357.

17. Tsuchiya Y, Takayanagi N, Sugiura H, et al. Lung diseases directly associated with rheumatoid arthritis and their relationship to outcome. Euro Respir J. 2011;37(6):1411-1417.

18. Myasoedova E, Davis JM 3rd, Crowson CS, Gabriel SE. Epidemiology of rheumatoid arthritis: rheumatoid arthritis and mortality. Curr Rheumatol Rep. 2010;12(5):379-385.

19. Brown KK. Rheumatoid lung disease. Proc Am Thorac Soc. 2007;4(5): 443-448.

20. Pappas DA, Giles JT, Connors G, Lechtzin N, Bathon JM, Danoff SK. Respiratory symptoms and disease characteristics as predictors of pulmonary function abnormalities in patients with rheumatoid arthritis: an observational cohort study. Arthritis Res Ther. 2010;12(3):R104.

21. Kanat F, Levendoglu F, Teke T. Radiological and functional assessment of pulmonary involvement in the rheumatoid arthritis patients. Rheumatol Int. 2007;27(5):459-466.

22. Bilgici A, Ulusoy H, Kuru O, Celenk C, Unsal M, Danaci M. Pulmonary involvement in rheumatoid arthritis. Rheumatol Int. 2005;25(6):429-435.

23. Fuld JP, Johnson MK, Cotton MM, et al. A longitudinal study of lung function in non-smoking patients with rheumatoid arthritis. Chest. 2003;124(4):1224-1231.

24. Avnon LS, Manzur F, Bolotin A, et al. Pulmonary functions testing in patients with rheumatoid arthritis. Isr Med Assoc J. 2009;11(2): 83-87.

25. Cortet B, Perez T, Roux N, et al. Pulmonary function tests and high resolution computed tomography of the lungs in patients with rheumatoid arthritis. Ann Rheum Dis. 1997;56(10):596-600.

26. Zrour SH, Touzi M, Bejia I, et al. Correlations between high-resolution computed tomography of the chest and clinical function in patients with rheumatoid arthritis. Prospective study in 75 patients. Joint Bone Spine. 2005;72(1):41-47.

27. Demir R, Bodur H, Tokoglu F, Olcay I, Ucan H, Borman P. High resolution computed tomography of the lungs in patients with rheumatoid arthritis. Rheumatol Int. 1999;19(1-2):19-22.

28. Hassan WU, Keaney NP, Holland CD, Kelly CA. High resolution computed tomography of the lung in lifelong non-smoking patients with rheumatoid arthritis. Ann Rheum Dis. 1995;54(4):308-310.
29. Perez T, Remy-Jardin M, Cortet B. Airways involvement in rheumatoid arthritis: clinical, functional, and HRCT findings. Am J Respir Crit Care Med. 1998;157(5 Pt 1):1658-1665.

30. Terasaki H, Fujimoto K, Hayabuchi N, Ogoh Y, Fukuda T, Muller NL. Respiratory symptoms in rheumatoid arthritis: relation between high resolution CT findings and functional impairment. Radiat Med. 2004;22(3):179-185.

31. Metafratzi ZM, Georgiadis AN, Ioannidou CV, et al. Pulmonary involvement in patients with early rheumatoid arthritis. Scand $J$ Rheumatol. 2007;36(5):338-344.

32. Garcia JG, Parhami N, Killam D, Garcia PL, Keogh BA. Bronchoalveolar lavage fluid evaluation in rheumatoid arthritis. Am Rev Respir Disease. 1986;133(3):450-454.

33. Gabbay E, Tarala R, Will R, et al. Interstitial lung disease in recent onset rheumatoid arthritis. Am J Respir Crit Care Med. 1997;156(2 Pt 1): 528-535.

34. Kolarz G, Scherak O, Popp W, et al. Bronchoalveolar lavage in rheumatoid arthritis. Br J Rheumatol. 1993;32(7):556-561.

35. Evans RB, Ettensohn DB, Fawaz-Estrup F, Lally EV, Kaplan SR. Gold lung: recent developments in pathogenesis, diagnosis, and therapy. Sem Arthritis Rheum. 1987;16(3):196-205.

36. Shettar SP, Chattopadhyay C, Wolstenholme RJ, Swinson DR. Diffuse alveolitis on a small dose of penicillamine. Br J Rheumatol. 1984;23(3):220-224.

37. Negishi M, Kaga S, Kasama T, et al. Lung injury associated with bucillamine therapy. Ryumachi. 1992;32(2):135-139. Japanese.

38. Inokuma $\mathrm{S}$. Leflunomide-induced interstitial pneumonitis might be a representative of disease-modifying antirheumatic drug-induced lung injury. Expert Opin Drug Saf. 2011;10(4):603-611.

39. Kremer JM, Alarcon GS, Weinblatt ME, et al. Clinical, laboratory, radiographic, and histopathologic features of methotrexate-associated lung injury in patients with rheumatoid arthritis: a multicenter study with literature review. Arthritis Rheum. 1997;40(10): 1829-1837.

40. Cannon GW. Methotrexate pulmonary toxicity. Rheum Dis Clin North Am. 1997;23(4):917-937.

41. Hamadeh MA, Atkinson J, Smith LJ. Sulfasalazine-induced pulmonary disease. Chest. 1992;101(4):1033-1037.

42. Chatterjee $\mathrm{S}$. Severe interstitial pneumonitis associated with infliximab therapy. Scand J Rheumatol. 2004;33(4):276-277.

43. Ostor AJ, Chilvers ER, Somerville MF, et al. Pulmonary complications of infliximab therapy in patients with rheumatoid arthritis. J Rheumatol. 2006;33(3):622-628.

44. Koike R, Tanaka M, Komano Y, et al. Tacrolimus-induced pulmonary injury in rheumatoid arthritis patients. Pulm Pharmacol Ther. 2011;24(4):401-406.

45. Miwa Y, Isozaki T, Wakabayashi K, et al. Tacrolimus-induced lung injury in a rheumatoid arthritis patient with interstitial pneumonitis. Mod Rheumatol. 2008;18(2):208-211.

46. Cottin V, Tebib J, Massonnet B, Souquet PJ, Bernard JP. Pulmonary function in patients receiving long-term low-dose methotrexate. Chest. 1996;109(4):933-938.

47. Kinder AJ, Hassell AB, Brand J, Brownfield A, Grove M, Shadforth MF The treatment of inflammatory arthritis with methotrexate in clinical practice: treatment duration and incidence of adverse drug reactions. Rheumatology. 2005;44(1):61-66.

48. Khadadah ME, Jayakrishnan B, Al-Gorair S, et al. Effect of methotrexate on pulmonary function in patients with rheumatoid arthritis - a prospective study. Rheumatol Int. 2002;22(5):204-207.

49. Dawson JK, Graham DR, Desmond J, Fewins HE, Lynch MP. Investigation of the chronic pulmonary effects of low-dose oral methotrexate in patients with rheumatoid arthritis: a prospective study incorporating HRCT scanning and pulmonary function tests. Rheumatology (Oxford). 2002;41(3):262-267.

50. Gaffo AL, Alarcon GS. Methotrexate is not associated with progression of interstitial lung disease in rheumatoid arthritis. Arch Intern Med. 2008;168(17):1927-1928. 
51. Gochuico BR, Avila NA, Chow CK, et al. Progressive preclinical interstitial lung disease in rheumatoid arthritis. Arch Intern Med. 2008;168(2):159-166.

52. Courtney PA, Alderdice J, Whitehead EM. Comment on methotrexate pneumonitis after initiation of infliximab therapy for rheumatoid arthritis. Arthritis Rheum. 2003;49(4):617; author reply 617-618.

53. Kramer N, Chuzhin Y, Kaufman LD, Ritter JM, Rosenstein ED. Methotrexate pneumonitis after initiation of infliximab therapy for rheumatoid arthritis. Arthritis Rheum. 2002;47(6):670-671.

54. Gottenberg JE, Ravaud P, Bardin T, et al. Risk factors for severe infections in patients with rheumatoid arthritis treated with rituximab in the autoimmunity and rituximab registry. Arthritis Rheum. 2010;62(9):2625-2632.

55. Hernandez-Cruz B, Garcia-Arias M, Ariza Ariza R, Martin Mola E. Rituximab in rheumatoid arthritis: a systematic review of efficacy and safety. Reumatol Clin. 2011;7(5):314-322. Spanish.

56. Ellman P, Ball RE. Rheumatoid disease with joint and pulmonary manifestations. Br Med J. 1948;2(4583):816-820.

57. Cudkowicz L, Madoff IM, Abelmann WH. Rheumatoid lung disease A case report which includes respiratory function studies and a lung biopsy. Br J Dis Chest. 1961;55:35-40.

58. Aronoff A, Bywaters EG, Fearnley GR. Lung lesions in rheumatoid arthritis. Br Med J. 1955;2(4933):228-232.

59. Talbott JA, Calkins E. Pulmonary involvement in rheumatoid arthritis JAMA. 1964;189:911-913.

60. Frank ST, Weg JG, Harkleroad LE, Fitch RF. Pulmonary dysfunction in rheumatoid disease. Chest. 1973;63(1):27-34.

61. Popper MS, Bogdonoff ML, Hughes RL. Interstitial rheumatoid lung disease. A reassessment and review of the literature. Chest. 1972;62(3): 243-250.

62. Popp W, Rauscher H, Ritschka L, et al. Prediction of interstitial lung involvement in rheumatoid arthritis. The value of clinical data, chest roentgenogram, lung function, and serologic parameters. Chest. 1992;102(2):391-394.

63. Cervantes-Perez P, Toro-Perez AH, Rodriguez-Jurado P. Pulmonary involvement in rheumatoid arthritis. JAMA. 1980;243(17): 1715-1719.

64. Fujii M, Adachi S, Shimizu T, Hirota S, Sako M, Kono M. Interstitial lung disease in rheumatoid arthritis: assessment with high-resolution computed tomography. J Thorac Imaging. 1993;8(1):54-62.

65. Dawson JK, Fewins HE, Desmond J, Lynch MP, Graham DR. Fibrosing alveolitis in patients with rheumatoid arthritis as assessed by high resolution computed tomography, chest radiography, and pulmonary function tests. Thorax. 2001;56(8):622-627.

66. Rajasekaran BA, Shovlin D, Lord P, Kelly CA. Interstitial lung disease in patients with rheumatoid arthritis: a comparison with cryptogenic fibrosing alveolitis. Rheumatology (Oxford). 2001;40(9): 1022-1025.

67. Horton MR. Rheumatoid arthritis associated interstitial lung disease. Crit Rev Comput Tomogr. 2004;45(5-6):429-440.

68. Bongartz T, Nannini C, Medina-Velasquez YF, et al. Incidence and mortality of interstitial lung disease in rheumatoid arthritis: a population-based study. Arthritis Rheum. 2010;62(6):1583-1591.

69. Jurik AG, Davidsen D, Graudal H. Prevalence of pulmonary involvement in rheumatoid arthritis and its relationship to some characteristics of the patients. A radiological and clinical study. Scand J Rheumatol. 1982;11(4):217-224.

70. Saag KG, Kolluri S, Koehnke RK, et al. Rheumatoid arthritis lung disease. Determinants of radiographic and physiologic abnormalities. Arthritis Rheum. 1996;39(10):1711-1719.

71. Banks J, Banks C, Cheong B, et al. An epidemiological and clinical investigation of pulmonary function and respiratory symptoms in patients with rheumatoid arthritis. $Q J$ Med. 1992;85(307-308):795-806.

72. Aubart F, Crestani B, Nicaise-Roland P, et al. High levels of anti-cyclic citrullinated peptide autoantibodies are associated with co-occurrence of pulmonary diseases with rheumatoid arthritis. $J$ Rheumatol. 2011;38(6):979-982.
73. Anaya JM, Diethelm L, Ortiz LA, et al. Pulmonary involvement in rheumatoid arthritis. Semin Arthritis Rheum. 1995;24(4): $242-254$.

74. Shidara K, Hoshi D, Inoue E, et al. Incidence of and risk factors for interstitial pneumonia in patients with rheumatoid arthritis in a large Japanese observational cohort, IORRA. Mod Rheumatol. 2010;20(3):280-286.

75. Tanaka N, Kim JS, Newell JD, et al. Rheumatoid arthritis-related lung diseases: CT findings. Radiology. 2004;232(1):81-91.

76. Sakaida $\mathrm{H}$. IgG rheumatoid factor in rheumatoid arthritis with interstitial lung disease. Ryumachi. 1995;35(4):671-677. Japanese.

77. Alexiou I, Germenis A, Koutroumpas A, Kontogianni A, Theodoridou K, Sakkas LI. Anti-cyclic citrullinated peptide-2 (CCP2) autoantibodies and extra-articular manifestations in Greek patients with rheumatoid arthritis. Clin Rheumatol. 2008;27(4):511-513.

78. Scott TE, Wise RA, Hochberg MC, Wigley FM. HLA-DR4 and pulmonary dysfunction in rheumatoid arthritis. Am J Med. 1987;82(4):765-771.

79. Charles PJ, Sweatman MC, Markwick JR, Maini RN. HLA-B40: a marker for susceptibility to lung disease in rheumatoid arthritis. Dis Markers. 1991;9(2):97-101.

80. Tanoue LT. Pulmonary manifestations of rheumatoid arthritis. Clin Chest Med. 1998;19(4):667-685, viii.

81. Hyland RH, Gordon DA, Broder I, et al. A systematic controlled study of pulmonary abnormalities in rheumatoid arthritis. $J$ Rheumatol. 1983;10(3):395-405.

82. Sugiyama Y, Ohno S, Kano S, Maeda H, Kitamura S. Diffuse panbronchiolitis and rheumatoid arthritis: a possible correlation with HLA-B54. Intern Med. 1994;33(10):612-614.

83. Hillarby MC, McMahon MJ, Grennan DM, et al. HLA associations in subjects with rheumatoid arthritis and bronchiectasis but not with other pulmonary complications of rheumatoid disease. Br J Rheumatol. 1993;32(9):794-797.

84. Michalski JP, McCombs CC, Scopelitis E, Biundo JJ Jr, Medsger TA Jr. Alpha 1-antitrypsin phenotypes, including M subtypes, in pulmonary disease associated with rheumatoid arthritis and systemic sclerosis. Arthritis Rheum. 1986;29(5):586-591.

85. Turesson C, Matteson EL, Colby TV, et al. Increased CD4+ T cell infiltrates in rheumatoid arthritis-associated interstitial pneumonitis compared with idiopathic interstitial pneumonitis. Arthritis Rheum. 2005;52(1):73-79.

86. Michel JJ, Turesson C, Lemster B, et al. CD56-expressing T cells that have features of senescence are expanded in rheumatoid arthritis. Arthritis Rheum. 2007;56(1):43-57.

87. Atkins SR, Turesson C, Myers JL, et al. Morphologic and quantitative assessment of CD20+ B cell infiltrates in rheumatoid arthritis-associated nonspecific interstitial pneumonia and usual interstitial pneumonia. Arthritis Rheum. 2006;54(2):635-641.

88. Song JW, Do KH, Kim MY, Jang SJ, Colby TV, Kim DS. Pathologic and radiologic differences between idiopathic and collagen vascular disease-related usual interstitial pneumonia. Chest. 2009;136(1): 23-30.

89. Ancochea J, Giron RM, Lopez-Botet M. Production of tumor necrosis factor alpha and interleukin- 6 by alveolar macrophages from patients with rheumatoid arthritis and interstitial pulmonary disease. Arch Bronconeumol. 1997;33(7):335-340. Spanish.

90. Horie S, Nakada K, Minota S, Kano S. High proliferative potential colony-forming cells (HPP-CFCs) in the peripheral blood of rheumatoid arthritis patients with interstitial lung disease. Scand J Rheumatol. 2003;32(5):273-276.

91. Albano SA, Santana-Sahagun E, Weisman MH. Cigarette smoking and rheumatoid arthritis. Sem Arthritis Rheum. 2001;31(3):146-159.

92. Jawaheer D, Gregersen PK. Rheumatoid arthritis. The genetic components. Rheum Dis Clin North Am. 2002;28(1):1-15, v.

93. Klareskog L, Stolt P, Lundberg K, et al. A new model for an etiology of rheumatoid arthritis: smoking may trigger HLA-DR (shared epitope)restricted immune reactions to autoantigens modified by citrullination. Arthritis Rheum. 2006;54(1):38-46. 
94. Makrygiannakis D, Hermansson M, Ulfgren AK, et al. Smoking increases peptidylarginine deiminase 2 enzyme expression in human lungs and increases citrullination in BAL cells. Ann Rheum Dis. 2008;67(10):1488-1492.

95. De Rycke L, Nicholas AP, Cantaert T, et al. Synovial intracellular citrullinated proteins colocalizing with peptidyl arginine deiminase as pathophysiologically relevant antigenic determinants of rheumatoid arthritis-specific humoral autoimmunity. Arthritis Rheum. 2005;52(8):2323-2330.

96. Bongartz T, Cantaert T, Atkins SR, et al. Citrullination in extraarticular manifestations of rheumatoid arthritis. Rheumatology (Oxford). 2007;46(1):70-75.

97. Stolt P, Bengtsson C, Nordmark B, et al. Quantification of the influence of cigarette smoking on rheumatoid arthritis: results from a population based case-control study, using incident cases. Ann Rheum Dis. 2003;62(9):835-841.

98. Ayhan-Ardic FF, Oken O, Yorgancioglu ZR, Ustun N, Gokharman FD. Pulmonary involvement in lifelong non-smoking patients with rheumatoid arthritis and ankylosing spondylitis without respiratory symptoms. Clin Rheumatol. 2006;25(2):213-218.

99. Biederer J, Schnabel A, Muhle C, Gross WL, Heller M, Reuter M. Correlation between HRCT findings, pulmonary function tests and bronchoalveolar lavage cytology in interstitial lung disease associated with rheumatoid arthritis. Eur Radiol. 2004;14(2):272-280.

100. Kim EJ, Elicker BM, Maldonado F, et al. Usual interstitial pneumonia in rheumatoid arthritis-associated interstitial lung disease. Eur RespirJ. 2010;35(6):1322-1328.

101. Lee HK, Kim DS, Yoo B, et al. Histopathologic pattern and clinical features of rheumatoid arthritis-associated interstitial lung disease. Chest. 2005;127(6):2019-2027.

102. Luqmani R, Hennell S, Estrach C, et al. British Society for Rheumatology and British Health Professionals in Rheumatology guideline for the management of rheumatoid arthritis (after the first 2 years). Rheumatology. 2009;48(4):436-439.

103. Roschmann RA, Rothenberg RJ. Pulmonary fibrosis in rheumatoid arthritis: a review of clinical features and therapy. Semin Arthritis Rheum. 1987;16(3):174-185.

104. Rajasekaran A, Shovlin D, Saravanan V, Lord P, Kelly C. Interstitial lung disease in patients with rheumatoid arthritis: comparison with cryptogenic fibrosing alveolitis over 5 years. J Rheumatol. 2006;33(7):1250-1253.

105. Provenzano G. Asymptomatic pulmonary involvement in RA. Thorax. 2002;57(2):187-188

106. Dawson JK, Fewins HE, Desmond J, Lynch MP, Graham DR. Predictors of progression of HRCT diagnosed fibrosing alveolitis in patients with rheumatoid arthritis. Ann Rheum Dis. 2002;61(6):517-521.

107. Shannon TM, Gale ME. Noncardiac manifestations of rheumatoid arthritis in the thorax. J Thorac Imaging. 1992;7(2):19-29.

108. McDonagh J, Greaves M, Wright AR, Heycock C, Owen JP, Kelly C. High resolution computed tomography of the lungs in patients with rheumatoid arthritis and interstitial lung disease. $\mathrm{Br} J$ Rheumatol. 1994;33(2):118-122.

109. Akira M, Sakatani M, Hara H. Thin-section CT findings in rheumatoid arthritis-associated lung disease: CT patterns and their courses. J Comput Assist Tomogr. 1999;23(6):941-948.

110. Kim EJ, Collard HR, King TE Jr. Rheumatoid arthritis-associated interstitial lung disease: the relevance of histopathologic and radiographic pattern. Chest. 2009;136(5):1397-1405.

111. Okuda Y, Takasugi K, Kurata N, Takahara J. Bronchoalveolar lavage fluid analysis in rheumatoid arthritis. Ryumachi. 1993;33(4):302-309. Japanese.

112. Gilligan DM, O’Connor CM, Ward K, Moloney D, Bresnihan B, FitzGerald MX. Bronchoalveolar lavage in patients with mild and severe rheumatoid lung disease. Thorax. 1990;45(8):591-596.

113. Tishler M, Grief J, Fireman E, Yaron M, Topilsky M. Bronchoalveolar lavage - a sensitive tool for early diagnosis of pulmonary involvement in rheumatoid arthritis. J Rheumatol. 1986;13(3):547-550.
114. Park JH, Kim DS, Park IN, et al. Prognosis of fibrotic interstitial pneumonia: idiopathic versus collagen vascular disease-related subtypes. Am J Respir Crit Care Med. 2007;175(7):705-711.

115. Devouassoux G, Cottin V, Liote H, et al. Characterisation of severe obliterative bronchiolitis in rheumatoid arthritis. Eur Respir J. 2009;33(5):1053-1061.

116. Rangel-Moreno J, Hartson L, Navarro C, Gaxiola M, Selman M, Randall TD. Inducible bronchus-associated lymphoid tissue (iBALT) in patients with pulmonary complications of rheumatoid arthritis. J Clin Invest. 2006;116(12):3183-3194.

117. Yousem SA, Colby TV, Carrington CB. Lung biopsy in rheumatoid arthritis. Am Rev Respir Dis. 1985;131(5):770-777.

118. Kinoshita F, Hamano H, Harada H, et al. Role of KL-6 in evaluating the disease severity of rheumatoid lung disease: comparison with HRCT. Respir Med. 2004;98(11):1131-1137.

119. Scott DG, Bacon PA. Response to methotrexate in fibrosing alveolitis associated with connective tissue disease. Thorax. 1980;35(10): $725-731$.

120. Cohen JM, Miller A, Spiera H. Interstitial pneumonitis complicating rheumatoid arthritis. Sustained remission with azathioprine therapy. Chest. 1977;72(4):521-524.

121. Chang HK, Park W, Ryu DS. Successful treatment of progressive rheumatoid interstitial lung disease with cyclosporine: a case report. J Korean Med Sci. 2002;17(2):270-273.

122. Saketkoo LA, Espinoza LR. Rheumatoid arthritis interstitial lung disease: mycophenolate mofetil as an antifibrotic and diseasemodifying antirheumatic drug. Arch Intern Med. 2008;168(15): 1718-1719.

123. Vassallo R, Matteson E, Thomas CF Jr. Clinical response of rheumatoid arthritis-associated pulmonary fibrosis to tumor necrosis factor-alpha inhibition. Chest. 2002;122(3):1093-1096.

124. Bargagli E, Galeazzi M, Rottoli P. Infliximab treatment in a patient with rheumatoid arthritis and pulmonary fibrosis. Eur Respir J. 2004;24(4):708.

125. Ostor AJ, Crisp AJ, Somerville MF, Scott DG. Fatal exacerbation of rheumatoid arthritis associated fibrosing alveolitis in patients given infliximab. BMJ. 2004;329(7477):1266.

126. Villeneuve E, St-Pierre A, Haraoui B. Interstitial pneumonitis associated with infliximab therapy. J Rheumatol. 2006;33(6):1189-1193.

127. Peno-Green L, Lluberas G, Kingsley T, Brantley S. Lung injury linked to etanercept therapy. Chest. 2002;122(5):1858-1860.

128. Hagiwara K, Sato T, Takagi-Kobayashi S, Hasegawa S, Shigihara N, Akiyama O. Acute exacerbation of preexisting interstitial lung disease after administration of etanercept for rheumatoid arthritis. J Rheumatol. 2007;34(5):1151-1154.

129. Dixon WG, Hyrich KL, Watson KD, Lunt M, Symmons DP. Influence of anti-TNF therapy on mortality in patients with rheumatoid arthritis-associated interstitial lung disease: results from the British Society for Rheumatology Biologics Register. Ann Rheum Dis. 2010;69(6):1086-1091.

130. Pratt DS, Schwartz MI, May JJ, Dreisin RB. Rapidly fatal pulmonary fibrosis: the accelerated variant of interstitial pneumonitis. Thorax. 1979;34(5):587-593.

131. Hakala M. Poor prognosis in patients with rheumatoid arthritis hospitalized for interstitial lung fibrosis. Chest. 1988;93(1): $114-118$

132. Hubbard R, Venn A. The impact of coexisting connective tissue disease on survival in patients with fibrosing alveolitis. Rheumatology (Oxford). 2002;41(6):676-679.

133. Turner-Warwick M, Burrows B, Johnson A. Cryptogenic fibrosing alveolitis: clinical features and their influence on survival. Thorax. 1980;35(3):171-180.

134. Saravanan V, Kelly CA. Survival in fibrosing alveolitis associated with rheumatoid arthritis is better than cryptogenic fibrosing alveolitis. Rheumatology (Oxford). 2003;42(4):603-604; author reply 604-605. 
Open Access Rheumatology Research and Reviews

Dovepress

\section{Publish your work in this journal}

Open Access Rheumatology Research and Reviews is an international, peer-reviewed, open access journal, publishing all aspects of clinical and experimental rheumatology in the clinic and laboratory including the following topics: Pathology, pathophysiology of rheumatologica diseases; Investigation, treatment and management of rheumatological

Submit your manuscript here: http://www.dovepress.com/open-access-rheumatology-research-and-reviews-journal diseases; Clinical trials and novel pharmacological approaches for the treatment of rheumatological disorders. The manuscript management system is completely online and includes a very quick and fair peerreview system, which is all easy to use. Visit http://www.dovepress.com/ testimonials.php to read real quotes from published authors. 